\title{
Iterated Block-Pulse Method for Solving Volterra Integral Equations
}

\author{
K. Maleknejad*, K. Mahdiani
}

Department of Applied Mathematics, Islamic Azad University, Karaj Branch, Karaj, Iran

\begin{abstract}
In this paper, an iterated method is presented to determine the numerical solution of linear Volterra integral equations of the second kind (VIEs2). This method initially uses the solution of the direct method to obtain the more accurate solution. The convergence and error analysis of this method are given. Finally, numerical examples illustrate efficiency and accuracy of the proposed method. Also, the numerical results of this method are compared with the results of direct method, collocation method and iterated collocation method.
\end{abstract}

Keywords Voltrra integral equations, Block-Pulse functions, Direct method, Iterated collocation method

\section{Introduction}

Block-Pulse functions (BPFs), a set of orthogonal functions with piecewise constant values, are studied and applied extensively as a useful tool in the analysis, synthesis, identification and other problems of control and systems science. In comparison with other basis functions or polynomials, BPFs can lead more easily to recursive computations to solve concrete problems[1] and among piecewise constant basis functions, the BPFs set has proved to be the most fundamental[2,3]. The complete details for BPFs are given in[1,4]. These functions have been directly used for solving different problems specially integral equations[5-10] as VIEs2 [1] (and references therein).

There are some iterated methods for solving integral equations for example the iterated collocation and Galerkin methods. These methods are studied and applied by many researchers[11,12]. Sloan[13] showed that an iterated solution of a VIE2 is always a good idea if the initial guess is the solution obtained by the Galerkin method, regardless of the size of $\|\mathrm{K}\|$. With collocation, the iterated solution is not always an improvement on the original collocation solution, but it is for many cases of interest[11].

In the present work, an iterated method for solving VIEs2 is applied. Using Block-Pulse functions (BPFs) and operational matrix of integration, VIE2 can be transformed to a lower triangular system of algebraic equations (direct method). Then the solution of this system is used to determine a new numerical solution of VIE2 which we call iterated Block-Pulse method. The results of convergence

* Corresponding author:

maleknejad@iust.ac.ir (K. Maleknejad)

Published online at http://journal.sapub.org/am

Copyright (C) 2012 Scientific \& Academic Publishing. All Rights Reserved show that the solution of this method can be at least as rapid as that of solution of direct method.

Section 2 of the paper introduces some preliminaries which are used through out this paper. The relations with small modifications of [1] are rewriten for the direct method in section 3. Then an approximation of a VIE solution is computed using iterated Block-Pulse method. The results of convergence and a error bound are given in section 4 . Numerical examples in section 5 illustrate efficiency and accuracy of the proposed method at mid-point of every subinterval. These results are compared with the results of direct method, collocation method and iterated collocation method.

\section{Preliminaries: Block-Pulse Functions}

We start by repeating some definitions, notations and basic facts; For more details see[8,15].

\subsection{Definition}

Let $\Delta_{\mathrm{m}}: 0=\mathrm{t}_{0}<\mathrm{t}_{1}<\cdots<\mathrm{t}_{\mathrm{m}}=1$, denote an uniform mesh on $[0,1]$ with

$$
\mathrm{t}_{\mathrm{i}}=\frac{\mathrm{i}}{\mathrm{m}}, \mathrm{i}=0,1, \cdots, \mathrm{m}, \mathrm{h}=\frac{1}{\mathrm{~m}} .
$$

An m-set of BPF's is defined on $\Omega=[0,1)$ as

$$
\phi_{\mathrm{i}}(\mathrm{t})=\left\{\begin{array}{cc}
1, & \mathrm{t} \in \Omega_{\mathrm{i}}, \\
0, & \text { otherwise, }
\end{array} \quad \Omega_{\mathrm{i}}=\left[\frac{\mathrm{i}-1}{\mathrm{~m}}, \frac{\mathrm{i}}{\mathrm{m}}\right),\right.
$$

where $\mathrm{i}=1,2, \cdots, \mathrm{m}$, with a positive integer value for $m$.

There are some properties for BPF's, the most important properties are disjointness, orthogonality and completeness.

\subsection{Vector Form}

The set of BPF's is written as 


$$
\Phi(\mathrm{t})=\left[\phi_{1}(\mathrm{t}), \phi_{2}(\mathrm{t}), \cdots, \phi_{\mathrm{m}}(\mathrm{t})\right]^{\mathrm{T}}, \quad \mathrm{t} \in[0,1) .
$$

So the disjointness property of BPF's follows

$$
\Phi(\mathrm{t}) \Phi^{\mathrm{T}}(\mathrm{t}) \mathrm{X}=\tilde{\mathrm{X}} \Phi(\mathrm{t}), \quad \tilde{\mathrm{X}}=\operatorname{diag} \mathrm{X},
$$

where $\mathrm{X}$ is an $m$-vector. Also, for any $m \times m$ matrix B

$$
\Phi^{\mathrm{T}}(\mathrm{t}) \mathrm{B} \Phi(\mathrm{t})=\hat{\mathrm{B}}^{\mathrm{T}} \Phi(\mathrm{t}),
$$

where $\hat{B}$ is a diagonal of matrix $B$.

\subsection{BPF's Expansion}

A function $\mathrm{f}(\mathrm{t}) \in \mathrm{l}^{2}([0,1))$, can be expanded by BPF's as

$$
\begin{gathered}
\mathrm{f}(\mathrm{t}) \approx \sum_{\mathrm{i}=1}^{\mathrm{m}} \mathrm{F}_{\mathrm{i}} \varphi_{\mathrm{i}}(\mathrm{t})=\mathrm{F}^{\mathrm{T}} \Phi(\mathrm{t})=\Phi^{\mathrm{T}}(\mathrm{t}) \mathrm{F}, \\
\mathrm{F}=\left[\mathrm{F}_{1}, \mathrm{~F}_{2}, \cdots, \mathrm{F}_{\mathrm{m}}\right]^{\mathrm{T}}, \quad \mathrm{F}_{\mathrm{i}}=\frac{1}{\mathrm{~h}} \int_{0}^{1} \mathrm{f}(\mathrm{t}) \phi_{\mathrm{i}}(\mathrm{t}) d \mathrm{dt} .
\end{gathered}
$$

Also kernel $\mathrm{k}(\mathrm{t}, \mathrm{s}) \in \mathrm{l}^{2}([0,1) \times[0,1))$, can be expanded as $\mathrm{k}(\mathrm{t}, \mathrm{s}) \approx \Phi^{\mathrm{T}}(\mathrm{t}) \mathrm{K} \Psi(\mathrm{s}), \quad \mathrm{k}_{\mathrm{ij}}=\frac{1}{\mathrm{~h}^{2}} \int_{(\mathrm{i}-1) \mathrm{h}}^{\mathrm{ih}} \int_{(\mathrm{j}-1) \mathrm{h}}^{\mathrm{jh}} \mathrm{k}(\mathrm{t}, \mathrm{s}) \mathrm{dsdt},(7)$ where $\Phi(\mathrm{t})$ and $\Psi(\mathrm{s})$ are $\mathrm{m}_{1}$ and $\mathrm{m}_{2}$ dimensional BPF vectors respectively, and $\mathrm{K}$ is the $\mathrm{m}_{1} \times \mathrm{m}_{2}$ Block-Pulse coefficients matrix with $\mathrm{k}_{\mathrm{ij}}$.

In this work, we set $\mathrm{m}_{1}=\mathrm{m}_{2}=\mathrm{m}$ and $\Psi(\mathrm{s})=\Phi(\mathrm{s})$.

\subsection{Operational matrix of integration}

Integral of $\Phi(t)$ is approximated by the following operational matrix of integration. This matrix is Teoplitze, so it can be used easily.

$$
\int_{0}^{\mathrm{t}} \Phi(\tau) \mathrm{d} \tau \approx \mathrm{P} \Phi(\mathrm{t}), \quad \mathrm{P}=\frac{\mathrm{h}}{2}\left(\begin{array}{ccccc}
1 & 2 & 2 & \ldots & 2 \\
0 & 1 & 2 & \ldots & 2 \\
0 & 0 & 1 & \ldots & 2 \\
\vdots & \vdots & \vdots & \ddots & \vdots \\
0 & 0 & 0 & \ldots & 1
\end{array}\right)_{\mathrm{m} \times \mathrm{m}}
$$

Also, from[8], we have

$$
\int_{0}^{\mathrm{t}} \mathrm{f}(\tau) \mathrm{d} \tau \approx \int_{0}^{\mathrm{t}} \mathrm{F}^{\mathrm{T}} \Phi(\tau) \mathrm{d} \tau \approx \mathrm{F}^{\mathrm{T}} \mathrm{P} \Phi(\mathrm{t}) .
$$

\section{Method: An Iterated Method for Solving a VIEs2}

In this section, an iterated method for solving linear Volterra integral equations of the second kind (VIEs2) is introduced. Here the BPFs are used to solve a VIEs2 directly. Then by using the obtained solution of Direct method, this integral equation is solved for second time. This new approximation is often an improvement on solution of the Direct method.

We consider a Volterra integral equation of second kind as

$$
x(t)=f(t)+\int_{0}^{t} k(t, s) x(s) d s, \quad t \in[0,1),
$$

where $\mathrm{x}(\mathrm{t})$ is unknown function, $\mathrm{f}(\mathrm{t}) \in \mathrm{l}^{2}([0,1))$ and $\mathrm{k}(\mathrm{t}, \mathrm{s}) \in \mathrm{l}^{2}([0,1) \times[0,1))$ are known.

\subsection{Direct Method}

The BPFs can be used to determine the numerical solution of Eq.(10) directly. The relations with small modification of [8] can be rewritten.

Setting approximation of functions $\mathrm{f}, \mathrm{x}$ and $\mathrm{k}$ with respect to the BPFs by using (5) and (7) in Eq.(10), we have

$$
\begin{aligned}
\mathrm{X}^{\mathrm{T}} \Phi(\mathrm{t}) & \approx \mathrm{F}^{\mathrm{T}} \Phi(\mathrm{t})+\int_{0}^{\mathrm{t}} \Phi^{\mathrm{T}}(\mathrm{t}) \mathrm{K} \Phi(\mathrm{s}) \Phi^{\mathrm{T}}(\mathrm{s}) X \mathrm{ds} \\
& =\mathrm{F}^{\mathrm{T}} \Phi(\mathrm{t})+\Phi^{\mathrm{T}}(\mathrm{t}) \mathrm{K} \int_{0}^{\mathrm{t}} \Phi(\mathrm{s}) \Phi^{\mathrm{T}}(\mathrm{s}) X d \mathrm{~s} .
\end{aligned}
$$

Using (3) and (9) follows:

$$
\mathrm{X}^{\mathrm{T}} \Phi(\mathrm{t}) \approx \mathrm{F}^{\mathrm{T}} \Phi(\mathrm{t})+\Phi^{\mathrm{T}}(\mathrm{t}) \mathrm{KX} \mathrm{X} \Phi(\mathrm{t}),
$$

in which $K \widetilde{X} P$ is an $m \times m$ matrix. By Eq.(4), we have

$$
\mathrm{X}^{\mathrm{T}} \Phi(\mathrm{t}) \approx \mathrm{F}^{\mathrm{T}} \Phi(\mathrm{t})+{\stackrel{\mathrm{X}^{\mathrm{T}}}{\mathrm{X}}}^{(\mathrm{t})},
$$

where $\hat{\mathrm{x}}$ is an $m$-vector with components equal to the diagonal entries of matrix $\mathrm{KX} P$ as

$$
\hat{X}_{i j}=\left\{\begin{array}{cc}
h K_{i j} X_{j}, & j<i, \\
\frac{h}{2} K_{i i} X_{i}, & i=j, \\
0, & \text { otherwise. }
\end{array}\right.
$$

So, Eq.(10) reduce to a linear lower triangular system as

$$
\mathrm{QX}=\mathrm{F} \text {, }
$$

with $\mathrm{X}=\left[\mathrm{X}_{1}, \mathrm{X}_{2}, \cdots, \mathrm{X}_{\mathrm{m}}\right]^{\mathrm{T}}, \mathrm{F}=\left[\mathrm{F}_{1}, \mathrm{~F}_{2}, \cdots, \mathrm{F}_{\mathrm{m}}\right]^{\mathrm{T}}$ and

$$
Q_{i j}=\left\{\begin{array}{cc}
-h K_{i j}, & j<i, \\
1-\frac{h}{2} K_{i i}, & i=j, \\
0, & \text { otherwise, }
\end{array}\right.
$$

where $\mathrm{K}$ is the $m \times m$ the Block-Pulse coefficients matrix with $\mathrm{K}_{\mathrm{ij}}$ that was defined in previous section. Unknown coefficients $X_{j}, j=1,2, \cdots, m$, are then calculated by solving this linear equations system. $x^{\Delta}(t)=\sum_{j=1}^{m} X_{j} \phi_{j}(t)$ is the solution of Eq.(10) by using direct method.

\subsection{Iterated Block-Pulse method}

The BPFs can be used for solving Eq.(10) again. Now by using the solution of direct method, an approximation of solution $x(t)$ of Eq.(10) is sought as

$$
\begin{aligned}
\mathrm{x}^{\mathrm{I}}(\mathrm{t}) & =\mathrm{f}(\mathrm{t})+\int_{0}^{\mathrm{t}} \mathrm{k}(\mathrm{t}, \mathrm{s}) \mathrm{x}^{\Delta}(\mathrm{s}) \mathrm{ds} \\
& =\mathrm{f}(\mathrm{t})+\sum_{\mathrm{j}=1}^{\mathrm{m}} \mathrm{X}_{\mathrm{j}} \beta_{\mathrm{j}}(\mathrm{t}),
\end{aligned}
$$

where $\mathrm{X}_{1}, \mathrm{X}_{2}, \cdots, \mathrm{X}_{\mathrm{m}}$ is the solution of the linear equations system (11) and

$$
\beta_{\mathrm{j}}(\mathrm{t})=\int_{0}^{\mathrm{t}} \mathrm{k}(\mathrm{t}, \mathrm{s}) \phi_{\mathrm{j}}(\mathrm{s}) \mathrm{ds}, 0 \leq \mathrm{t}<1 .
$$

Using the definition of the BPFs and the assumption that $\mathrm{t} \in \Omega_{\mathrm{i}}$, (12) and (13) can be written as

$$
\mathrm{x}^{\mathrm{I}}(\mathrm{t})=\mathrm{f}(\mathrm{t})+\sum_{\mathrm{j}=1}^{\mathrm{i}-1} \mathrm{X}_{\mathrm{j}} \beta_{\mathrm{j}}(\mathrm{t})+\mathrm{X}_{\mathrm{i}} \alpha_{\mathrm{i}}(\mathrm{t}),
$$




$$
\beta_{\mathrm{j}}(\mathrm{t})=\int_{\mathrm{t}_{\mathrm{j}-1}}^{\mathrm{t}_{\mathrm{j}}} \mathrm{k}(\mathrm{t}, \mathrm{s}) \mathrm{ds}, \quad \alpha_{\mathrm{i}}(\mathrm{t})=\int_{\mathrm{t}_{\mathrm{i}-1}}^{\mathrm{t}} \mathrm{k}(\mathrm{t}, \mathrm{s}) \mathrm{ds} .
$$

Now an auxiliary mesh can be introduced as $\hat{t}_{i}=\frac{2 i-1}{2 n}, \quad i=1,2, \cdots, m$, and $t$ can be replaced in (14) by $\wedge$

$t_{i}$. This method is called the iterated Block-Pulse method.

\section{Error Bound and Convergence of Method}

In this section, convergence of the iterated Block-Pulse method is considered. An error bound is given for obtained solution of this method. Eqs.(10) and (12) can be written in the operator form

$$
x=f+K x, \quad x^{I}=f+K x^{\Delta},
$$

respectively. Using (15), we have

$$
\begin{gathered}
x-x^{I}=x-f-K x^{\Delta} \\
=f+K x-f-K x^{\Delta} \\
=K\left(x-x^{\Delta}\right),
\end{gathered}
$$

and

$$
\left\|\mathrm{x}-\mathrm{x}^{\mathrm{I}}\right\| \leq\|\mathrm{K}\|\left\|\mathrm{x}-\mathrm{x}^{\Delta}\right\|, \quad\|\mathrm{K}\|_{1^{2} \rightarrow \mathrm{l}^{2}}=\sup _{\Omega} \int_{\Omega}|\mathrm{k}(\mathrm{t}, \mathrm{s})| \mathrm{ds} .
$$

If $\|\mathrm{K}\|<1$, then the convergence of $x^{I}$ to $x$ is at least as rapid as that of $x^{\Delta}$ to $x$.

\section{Numerical Examples}

In this section, the proposed method is used to determine the numerical solution of some examples. The numerical results are given in the tables for the error of approximation at the mid-point of every subinterval with $n=8,16,32,64$. These results are compared with the results of direct, collocation and iterated collocation methods. The maximum norm of error for iterated Block-Pulse, direct, collocation and iterated collocation methods is denoted with $\left\|\mathrm{e}^{\mathrm{I}}\right\|_{\infty}$, $\left\|\mathrm{e}^{\Delta}\right\|_{\infty},\left\|\mathrm{e}^{\mathrm{C}}\right\|_{\infty}$ and $\left\|\mathrm{e}^{\mathrm{IC}}\right\|_{\infty}$, respectively. In the collocation method, BPFs are applied as a set of basis functions.

Example 1. Consider the Volterra integral equation of second kind [5]:

$$
x(t)=f(t)+\int_{0}^{t}(t-s) \cos (t-s) x(s) d s,
$$

where $f(t)=\cos t, t \in[0,1)$. The exact solution of this equation is $x(t)=\frac{1}{3}(2 \cos \sqrt{3} t+1)$.

See Table 1 for numerical results of the maximum norm of error by using four methods at mid-point of every subinterval. The results show that the error of the iterated Block-Pulse method is smaller than the error of the direct method.The collocation method and the iterated collocation method have the same results. The error of the iterated Block-Pulse method is smaller than the error of the iterated collocation method.

Table 1. Errors of four methods for Example 1

\begin{tabular}{|c|c|c|c|c|}
\hline $\mathrm{t}$ & 8 & 16 & 32 & 64 \\
\hline$\left\|\mathrm{e}^{\mathrm{I}}\right\|_{\infty}$ & $0.6837 \times 10^{-4}$ & $0.1910 \times 10^{-4}$ & $0.5044 \times 10^{-5}$ & $0.1296 \times 10^{-5}$ \\
\hline$\left\|\mathrm{e}^{\Delta}\right\|_{\infty}$ & $0.1300 \times 10^{-2}$ & $0.3254 \times 10^{-3}$ & $0.8137 \times 10^{-4}$ & $0.2034 \times 10^{-4}$ \\
\hline$\left\|\mathrm{e}^{\mathrm{C}}\right\|_{\infty}$ & $0.3151 \times 10^{-3}$ & $0.8053 \times 10^{-4}$ & $0.2030 \times 10^{-4}$ & $0.5091 \times 10^{-5}$ \\
\hline$\left\|\mathrm{e}^{\mathrm{IC}}\right\|_{\infty}$ & $0.3151 \times 10^{-3}$ & $0.8053 \times 10^{-4}$ & $0.2030 \times 10^{-4}$ & $0.5091 \times 10^{-5}$ \\
\hline
\end{tabular}

Example 2. For the Volterra integral equation of second kind [5]:

$$
x(t)=f(t)+\int_{0}^{t}(t-s) x(s) d s,
$$

with $f(t)=\sin t, t \in[0,1)$, the exact solution is $x(t)=\frac{1}{2}(\sin t+\sinh t)$.

Table 2 shows numerical results for the maximum norm of error by using four methods at the mid-point of every subinterval. The maximum norm of error for the iterated Block-Pulse method is smaller than all the others. But, the numerical results for this example are very close to each other.

Table 2. Errors of four methods for Example 2

\begin{tabular}{|c|c|c|c|c|}
\hline$t$ & 8 & 16 & 32 & 64 \\
\hline$\left\|\mathrm{e}^{\mathrm{I}}\right\|_{\infty}$ & $0.1040 \times 10^{-2}$ & $0.2658 \times 10^{-3}$ & $0.6714 \times 10^{-4}$ & $0.16876 \times 10^{-4}$ \\
\hline$\left\|\mathrm{e}^{\Delta}\right\|_{\infty}$ & $0.1324 \times 10^{-2}$ & $0.3446 \times 10^{-3}$ & $0.8785 \times 10^{-4}$ & $0.2217 \times 10^{-4}$ \\
\hline$\left\|\mathrm{e}^{\mathrm{C}}\right\|_{\infty}$ & $0.1413 \times 10^{-2}$ & $0.3684 \times 10^{-3}$ & $0.9402 \times 10^{-4}$ & $0.2375 \times 10^{-4}$ \\
\hline$\left\|\mathrm{e}^{\mathrm{IC}}\right\|_{\infty}$ & $0.1413 \times 10^{-2}$ & $0.3684 \times 10^{-3}$ & $0.9402 \times 10^{-4}$ & $0.2375 \times 10^{-4}$ \\
\hline
\end{tabular}

Example 3. The Volterra integral equation of second kind [9]:

$$
x(t)=f(t)-\int_{0}^{t}\left(3 t+2 t^{3}-s\right) /\left(1+t^{2}\right)^{2} x(s) d s,
$$

where $f(t)=\left(3 t+2 t^{3}\right) / 3\left(1+t^{2}\right)^{2}, t \in[0,1)$, has the exact solution $x(t)=t /\left(1+t^{2}\right)^{5 / 2}$. See Table 3 for numerical results of the maximum norm of error by using four methods at the mid-point of every subinterval. The maximum norm of error for the iterated Block-Pulse method is smaller than all the others. But, the numerical results for this example are very close to each other.

Table 3. Errors of four methods f or Example 3

\begin{tabular}{|c|c|c|c|c|}
\hline$t$ & 8 & 16 & 32 & 64 \\
\hline$\left\|\mathrm{e}^{\mathrm{I}}\right\|_{\infty}$ & $0.7960 \times 10^{-3}$ & $0.2058 \times 10^{-3}$ & $0.5178 \times 10^{-4}$ & $0.1295 \times 10^{-4}$ \\
\hline$\left\|\mathrm{e}^{\Delta}\right\|_{\infty}$ & $0.1356 \times 10^{-2}$ & $0.3475 \times 10^{-3}$ & $0.8704 \times 10^{-4}$ & $0.2277 \times 10^{-4}$ \\
\hline$\left\|\mathrm{e}^{\mathrm{C}}\right\|_{\infty}$ & $0.8721 \times 10^{-3}$ & $0.2208 \times 10^{-3}$ & $0.5505 \times 10^{-4}$ & $0.1379 \times 10^{-4}$ \\
\hline$\left\|\mathrm{e}^{\mathrm{IC}}\right\|_{\infty}$ & $0.8721 \times 10^{-3}$ & $0.2208 \times 10^{-3}$ & $0.5505 \times 10^{-4}$ & $0.1379 \times 10^{-4}$ \\
\hline
\end{tabular}




\section{Conclusions}

In the present paper, a new iterated method for solving VIEs2 using BPFs was proposed. This method initially used the solution of the direct method to obtain the more accurate solution. The convergence and error analysis of this method were given. The results of convergence showed that the solution of this method can be at least as rapid as that of direct method. The numerical results of this method were compared with direct, collocation and iterated collocation methods. Similar to the iterated collocation method, the iterated solution is not always an improvement on the original direct solution, but it is for many cases of interest.

\section{REFERENCES}

[1] Jiang, ZH., and Schaufelberger, W., 1992, Block Pulse Functions and Their Applications in Control Systems, Berlin, Springer-Verlag.

[2] Beauchamp, KG., 1984, Applications of Walsh and Related Functions with an Introduction to Sequency theory, Academic Press, London.

[3] Deb, A., Sarkar, G., and Sen, SK., 1994, Block pulse functions, the most fundamental of all piecewise constant basis functions, Int J Syst Sci., 25(2), 351-363.

[4] Rao, GP., 1983, Piecewise constant orthogonal functions and their application to systems and control, Springer-Verlag, New York.

[5] Babolian, E., and Masouri, Z., 2008, Direct method to solve Volterra integral equation of the first kind using operational matrix with block-pulse functions, J. Comput. Appl. Math., 220, 51-57.
[6] Maleknejad, K., and Mahmoudi, Y., 2004, Numerical solution of linear Fredholm integral equation by using hybrid Taylor and Block-Pulse functions, Appl. Math. Comput., 149, 799-806.

[7] Maleknejad, K., and Mahdiani, K., 2011, Solving nonlinear mixed Volterra-Fredholm integral equations with two dimensional block-pulse functions using direct method, Common Nonlinear Sci Numer Simulat 16, 3512-3519.

[8] Maleknejad, K., Sohrabi, S., and Baranji, B., 2010, Application of 2D-BPFs to nonlinear integral equations, Common Nonlinear Sci Numer Simulat, 15(3), 528-535.

[9] Maleknejad, K., Shahrezaee, M., and Khatami, H., 2005, Numerical solution of integral equations system of the second kind by Block-Pulse functions, Appl. Math. Comp., 166, 15-24.

[10] Maleknejad, K., and Tavassoli Kajani, M., 2003, Solving second kind integral equations by Galerkin methods with hybrid Legendre and Block-Pulse functions, Appl. Math. Comp., 145, 623-629.

[11] Atkinson, K., 1997, The Numerical Solution of Integral Equations of the Second Kind, Cambridge University Press.

[12] Brunner, H., 2004, Collocation Methods for Volterra Integral and Related Functional Equations, Cambridge University Press.

[13] Sloan, I., 1976, Improvement by iteration for compact operator equations, Math Comp., 30, 758-764.

[14] Blyth, W. F., May, R. L., and Widyaningsih, P., 2004, Volterra integral equations solved in Fredholm form using Walsh functions, Anziam J., 45(E), C269-C282.

[15] Krasnov, M., Kiselev, A., and Makarenko, G., 1971, Problems And Exercises in Integral Equations, Mir Publishers, Moscow. 